\title{
Corosolic acid induces cell cycle arrest and cell apoptosis in human retinoblastoma Y-79 cells via disruption of MELK-FoxM1 signaling
}

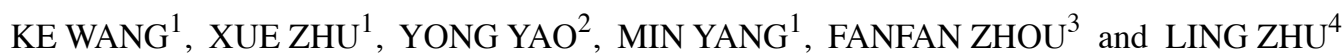 \\ ${ }^{1}$ Key Laboratory of Nuclear Medicine, Ministry of Health, Jiangsu Key Laboratory of Molecular Nuclear Medicine, \\ Jiangsu Institute of Nuclear Medicine, Wuxi, Jiangsu 214063; ${ }^{2}$ Department of Ophthalmology, \\ Wuxi People's Hospital Affiliated to Nanjing Medical University, Wuxi, Jiangsu 214023, P.R. China; \\ ${ }^{3}$ Faculty of Pharmacy, and ${ }^{4}$ Save Sight Institute, University of Sydney, Sydney, NSW 2000, Australia
}

Received November 27, 2017; Accepted March 23, 2018

DOI: 10.3892/or.2018.6339

\begin{abstract}
Retinoblastoma $(\mathrm{Rb})$ is the most frequent primary intraocular tumor usually diagnosed in infants and children, and current therapy for such disease is still limited. Corosolic acid (CA), an ursane-type pentacyclic triterpene, has been assessed as a promising anticancer agent with little impact on untransformed cells. In the present study, we investigated the cytotoxic effect and underlying mechanism of CA on human retinoblastoma Y-79 cells. The viability of cells was verified by MTT assay. Cell cycle and apoptosis were evaluated by flow cytometric analysis. The expressions and activities of the related molecules were assessed by western blot analysis and luciferase assay. The results demonstrated that the treatment of CA dose-dependently induced cytotoxicity, cell cycle arrest and cell apoptosis in Y-79 cells. Furthermore, MELK-FoxM1 signaling was estimated to be involved in the cytotoxic effect of CA on Y-79 cells, and CA exerted its activity mainly through inhibition of the expression levels of MELK and FoxM1 as well as through suppression of the transcriptional activity of FoxM1 driven by itself or MELK. Our findings establish MELK-FoxM1 signaling as a promising therapeutic target for human retinoblastoma, and suggest the potential development of CA and its derivatives as novel drug candidates against this disease.
\end{abstract}

Correspondence to: Dr Yong Yao, Department of Ophthalmology, Wuxi People's Hospital Affiliated to Nanjing Medical University, 299 Qingyang Road, Wuxi, Jiangsu 214023, P.R. China

E-mail: wxry_yaoyong@outlook.com

Dr Min Yang, Key Laboratory of Nuclear Medicine, Ministry of Health, Jiangsu Key Laboratory of Molecular Nuclear Medicine, Jiangsu Institute of Nuclear Medicine, 20 Qianrong Road, Wuxi, Jiangsu 214063, P.R. China

E-mail: yangmin@jsinm.org

Key words: retinoblastoma, corosolic acid, cell cycle arrest, cell apoptosis, MELK-FoxM1 signaling

\section{Introduction}

Retinoblastoma is the most common primary intraocular tumor in infants and children, affecting 1:14,000-1:22,000 live births (1-3). It is confirmed to be initiated by a bi-allelic inactivation of the retinoblastoma $\mathrm{Rbl}$ gene in retinal cells in both the hereditary and sporadic types (4). Lack of a functional $\mathrm{pRb} 1$ induces defective differentiation and uncontrolled proliferation of a subset of human retinal cells, which then develop into tumors (5). Current therapy for retinoblastoma include local control of small to intermediate size tumors with laser combined with radiation and/or chemotherapy, or enucleation combined with or without systemic chemotherapy $(6,7)$. Despite the progress in the treatment of retinoblastoma, significant issues remain unsolved. Enucleation of the eye leads to loss of vision and facial deformity (8), and radiotherapy and traditional chemotherapy increase the risk for the development of secondary tumors, such as osteosarcoma and melanoma $(9,10)$. Therefore, the development of novel and effective moleculartargeted chemotherapeutic agents is needed for retinoblastoma treatment.

Ursane-type pentacyclic triterpenes, abundantly found in the plant kingdom, have been proposed to be a class of promising agents for cancer therapy (11). Of these compounds, ursolic acid (UA) is a prevalent pentacyclic triterpenoid and exhibits remarkable cytotoxic activity in various types of cancer cells (12-14). Such a compound exerts anticancer activity via induction of cell cycle arrest and cell apoptosis as well as inhibition of cell migration $(15,16)$. Corosolic acid (CA) (Fig. 1A) is one analog of UA, and shows higher cytotoxic activity compared to UA in some types of cancer cells; however, the regulatory effect and underlying mechanism of CA on retinoblastoma is unexplored (17). In the present study, experiments were first designed to evaluate the cytotoxic effect of CA on Y-79 cells, an in vitro model of human retinoblastoma.

FoxM1, also known as FKHL16, MPP2 or TRIDENT, is a member of the Forkhead superfamily of transcription factors and plays a key role in the regulation of a variety of essential biological processes (18). Existing evidence has confirmed that FoxM1 closely participates in human cancers through inducing 
cancer initiation and promoting cancer progression (19). A recent study has revealed that the transcriptional activity of FoxM1 is regulated by maternal embryonic leucine-zipper kinase (MELK), a serine/threonine kinase (20). Joshi et al (21) demonstrated that MELK and FoxM1 are highly co-expressed, co-regulated and functionally related in glioblastoma multiforme (GBM), and that MELK is involved in the regulatory effect of FoxM1 on cancer cell survival. However, the role of MELK-FoxM1 signaling in retinoblastoma has never been investigated. A previous study by Wang et al (22) has confirmed that FoxM1 is a direct target of UA in MCF-7 human breast cancer cells. Due to the similar structure, the involvement of MELK-FoxM1 signaling in the effect of CA on Y-79 cells is further investigated.

\section{Materials and methods}

Chemicals and reagents. Corosolic acid (analytical standard, 89067) was purchased from Sigma-Aldrich (Merck KGaA, Darmstadt, Germany) and dissolved in dimethyl sulfoxide (DMSO). RPMI-1640 medium, DMEM/F12 medium, fetal bovine serum (FBS) and penicillin-streptomycin solution were obtained from Gibco (Grand Island, NY, USA). DMSO, 3-(4,5-dimethylthiazol-2-yl)-2,5-diphenyltetrazolium bromide (MTT), propidium iodide (PI) and glutamine were obtained from Sigma-Aldrich (Merck KGaA, Darmstadt, Germany). Lipofectamine 2000 was obtained from Invitrogen (Carlsbad, CA, USA).The kit for apoptosis was obtained from BD Biosciences (San Jose, CA, USA). The antibodies used in the present study were as follows: p53 (cat. no. 48818; Cell Signaling Technology, Inc., Danvers, MA, USA), p21 (cat. no. ab109520; Abcam, Cambridge, MA, USA), cyclin B1 (cat. no. 4135; Cell Signaling Technology, Inc. Danvers, MA, USA), Cdc25B (cat. no. ab124819; Abcam), Bax (cat. no. 2774; Cell Signaling Technology, Inc.), Bcl-2 (cat. no. 15071; Cell Signaling Technology, Inc.), caspase-9 (cat. no. ab32539; Abcam), caspase-3 (cat. no. 9662), ASK1 (cat. no. 3762), p-JNK (cat. no. 9255), JNK (cat. no. 9252), p-p38 (cat. no. 9216), p38 (cat. no. 9212), FoxM1 (cat. no. 5436), MELK (cat. no. 2274), $\beta$-actin (cat. no. 4970; all were from Cell Signaling Technology, Inc.) and the HRP conjugated goat anti-mouse (sc-2031)/rabbit(sc-2030) secondary antibodies (Santa Cruz Biotechnology, Inc., Dallas, TX, USA). All other chemicals and reagents were purchased from Beyotime Institute of Biotechnology (Nantong, China).

Cell culture and transfection. The human retinoblastoma cell line Y-79 and the human RPE cell line ARPE-19 were obtained from the American Type Culture Collection (ATCC, Manassas, VA, USA). Y-79 cells were cultured in RPMI-1640 medium with $10 \%$ FBS and $1 \%$ penicillin-streptomycin $(\mathrm{P} / \mathrm{S})$. ARPE-19 cells were cultured in DMEM/F12 medium with $10 \%$ FBS, 2 mM glutamine and 1\% P/S. Cells were maintained at $37^{\circ} \mathrm{C}$ in a humidified atmosphere containing $5 \% \mathrm{CO} 2$ and passaged once every 3 days. For the analysis of function of MELK-FoxM1 signaling, cells were transiently transfected with the indicated plasmids [FoxM1-luc reporter vector $(2 \mu \mathrm{g}$, provided by Dr Fanfan Zhou's Laboratory, University of Sydney), FoxM1 expression vector ( $2 \mu \mathrm{g}$, pCW57.1-FOXM1b plasmid; cat. no. 68811; Addgene, Cambridge, MA, USA) or MELK expression vector $(2 \mu \mathrm{g}$,provided by Dr Fanfan Zhou's Laboratory, University of Sydney)] or small interfering RNA for MELK (100 pmol MELK siRNA; cat. no. sc-61016; Santa Cruz Biotechnology, Inc.) using Lipofectamine 2000. Cells were cultured for $24 \mathrm{~h}$ post transfection and the expressions of the related molecules were assessed by western blot analysis before treatment with the indicated agents.

Measurement of cell viability. To assess the effect of CA on cell viability, MTT assay was used as previously mentioned (23). After treatment, $10 \mu \mathrm{l}$ of MTT ( $5 \mathrm{mg} / \mathrm{ml}$ stock in PBS) was added per well and the incubation was continued for $2 \mathrm{~h}$. Then, the culture medium was removed and $100 \mu 1$ DMSO was added to dissolve the formazan crystals. The absorbance at $570 \mathrm{~nm}$ was determined with an ELISA reader (Bio-Rad Laboratories, Hercules, CA, USA).

Measurement of cell cycle distribution. To assess the effect of CA on cell cycle distribution, PI staining was used as previously mentioned (24). After treatment, cells were collected by centrifugation, fixed in $70 \%$ ethanol, re-suspended in PBS containing RNase $(1 \mathrm{mg} / \mathrm{ml})$ and PI $(50 \mu \mathrm{g} / \mathrm{ml})$, incubated for $30 \mathrm{~min}$ in the dark and then analyzed using flow cytometry (Becton-Dickinson; BD Biosciences).

Measurement of cell apoptosis. To assess the effect of CA on cell apoptosis, double staining with Annexin V-FITC and PI was used as previously described (24). After treatment, cells were collected by centrifugation, washed twice with cold PBS, re-suspended in binding buffer containing $10 \mu \mathrm{l}$ of Annexin V-FITC stock and $10 \mu \mathrm{l}$ of PI, and then analyzed using flow cytometry (Becton-Dickinson; BD Biosciences).

Western blot analysis. To assess the effect of CA on the expression profiles of related proteins, western blot analysis was used as previously described (25). After treatment, cells were lysed for $20 \mathrm{~min}$ in lysis buffer and the concentration of protein sample was determined with the Bradford method. Samples $(50 \mu \mathrm{g})$ were separated on SDS-PAGE gel (10\%) and electrophoretically transferred onto polyvinylidene fluoride (PVDF) membrane. After blocking, the membrane was incubated with the primary antibody at $4^{\circ} \mathrm{C}$ for overnight and horseradish peroxidase (HRP)-conjugated secondary antibody at $37^{\circ} \mathrm{C}$ for $2 \mathrm{~h}$. The protein bands were visualized by ECL detection kit (Beyotime Institute of Biotechnology).

Luciferase assay. To assess the effect of CA on the transcriptional activity of FoxM1, luciferase assay was used as previously described (26). After transfection, cells were treated with the indicated agents for $24 \mathrm{~h}$ and the luciferase activity was measured using luciferase assay system. Relative luciferase activity was expressed as percentage induction of promoter activity by the FoxM1 expression vector, where the promoter activity resulting from transfection with FoxM1 was set at $100 \%$.

Statistical analysis. Biostatistical analyses were conducted with Prism 5.0 (GraphPad Software, Inc., La Jolla, CA, USA) and SPSS 16.0 software package (SPSS, Inc., Chicago, IL, USA). All experiments were conducted in triplicate and the 
A

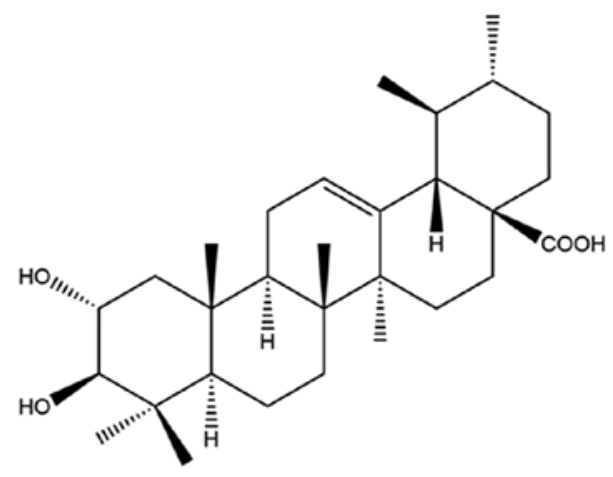

B

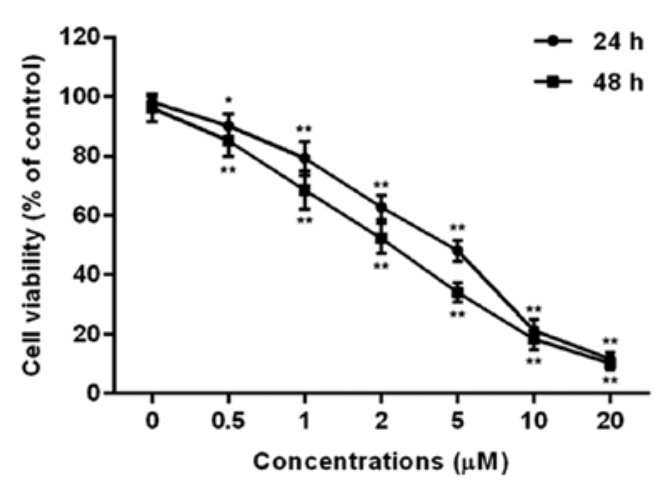

C

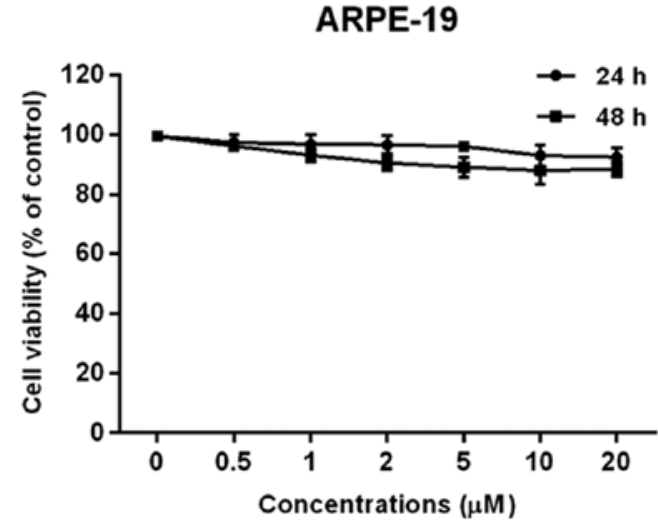

Figure 1. Effect of corosolic acid (CA) on cell proliferation in human retinoblastoma Y-79 cells and ARPE-19 human retinal pigment epithelial cells. (A) The chemical structure of CA. (B) Y-79 cells were treated with CA $(0,0.5,1,2,5,10$ and $20 \mu \mathrm{M})$ for 24 or $48 \mathrm{~h}$, and cell viability was assessed by MTT assay. (C) ARPE-19 cells were treated with CA $(0,0.5,1,2,5,10$ and $20 \mu \mathrm{M})$ for 24 or $48 \mathrm{~h}$, and cell viability was assessed by MTT assay. All data are expressed as means $\pm \mathrm{SD}$ of three experiments and each experiment included triplicate repeats. ${ }^{*} \mathrm{P}<0.05,{ }^{* *} \mathrm{P}<0.01$ vs. the control.

results were indicative of three independent studies. Data are expressed as means $\pm \mathrm{SD}$ and statistical comparisons were made using the Student's t-test and the one-way ANOVA. A $\mathrm{P}<0.05$ was considered to indicate a statistically significant result.

\section{Results}

Cytotoxic effect of CA on cell proliferation in human retinoblastoma Y-79 cells. In order to analyze the biological effect of CA, human retinoblastoma Y-79 cells were treated with various concentrations of CA for 24 or $48 \mathrm{~h}$ and cell viability was assessed by MTT assay. The results demonstrated that CA significantly inhibited cell proliferation of Y-79 cells in a dose- and time-dependent manner (Fig. 1B). The value of $\mathrm{IC}_{50}$ was calculated using the GraphPad Prism software. The results indicated that treatment of $4.15 \mu \mathrm{M} \mathrm{CA}$ for $24 \mathrm{~h}$ or $3.37 \mu \mathrm{M}$ for $48 \mathrm{~h}$ resulted in a reduced cell proliferation by $50 \%$ in the Y-79 cells. However, CA treatment had little impact on untransformed cells such as the human retinal pigment epithelial cell line ARPE-19 (Fig. 1C). Then, treatment with concentrations of 2,5 and $10 \mu \mathrm{M} \mathrm{CA}$ for $24 \mathrm{~h}$ was selected to continue this study. The data suggest that CA has an inhibitory effect against human retinoblastoma Y-79 cells.

Promotive effect of $C A$ on cell cycle arrest in human retinoblastoma Y-79 cells. In order to identify whether CA induces proliferation inhibition via triggering cell cycle arrest, human retinoblastoma Y-79 cells were treated with CA $(0,2,5$ and $10 \mu \mathrm{M})$ for $24 \mathrm{~h}$, and cell cycle distribution was assessed by flow cytometric analysis. The results indicated that CA treatment $(10 \mu \mathrm{M})$ significantly increased the population of cells in the $\mathrm{G} 2 / \mathrm{M}$ phase to $32.14 \pm 1.37$ compared to the non-treatment cells (12.53 \pm 1.18$)$ (Fig. 2). Furthermore, the change in cell cycle regulators upon $\mathrm{CA}$ treatment was analyzed using western blot analysis. As shown in Fig. 3, CA treatment dose-dependently affected the cell phase distribution via inducing upregulation of p53 and p21WAF1 as well as downregulation of cyclin B1, Cdc25B and Aurora B in the Y-79 cells.

Promotive effect of CA on cell apoptosis in human retinoblastoma Y-79 cells. In order to identify whether CA induces proliferation inhibition via triggering cell apoptosis, human retinoblastoma Y-79 cells were treated with CA $(0,2$, 5 and $10 \mu \mathrm{M}$ ) for $24 \mathrm{~h}$, and cell apoptosis was assessed by flow cytometric analysis. The results indicated that CA treatment $(10 \mu \mathrm{M})$ significantly increased the percentage of apoptotic cells to $54.58 \pm 4.46$ compared to the non-treatment cells $(1.18 \pm 0.25 \%)$ (Fig. 4). Furthermore, the change in cell apoptosis-related signaling pathways upon CA treatment was analyzed. First, as shown in Fig. 5A, CA treatment dose-dependently affected the mitochondrial pathway via inducing upregulation of Bax, downregulation of Bcl-2 and cleavage of caspase-9 and caspase-3. Then, as shown in Fig. 5B, 
A
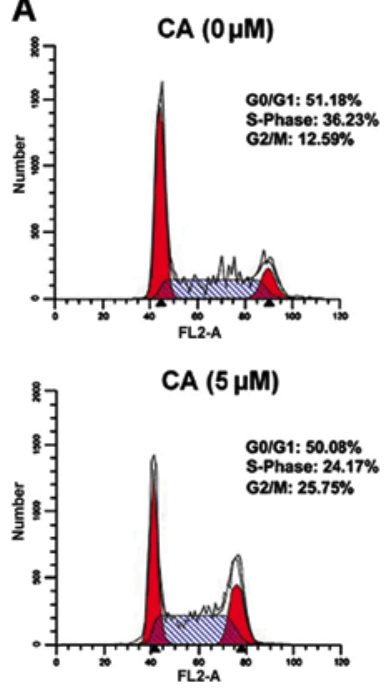

$\mathrm{CA}(2 \mu \mathrm{M})$

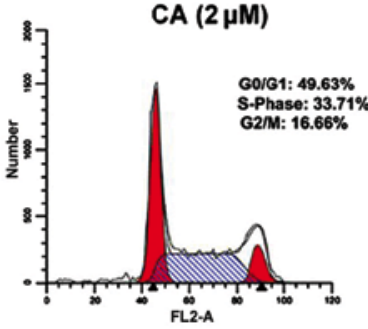

$\mathrm{CA}(10 \mu \mathrm{M})$

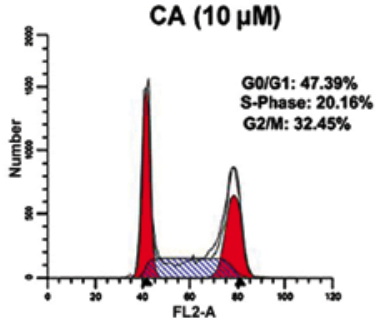

B

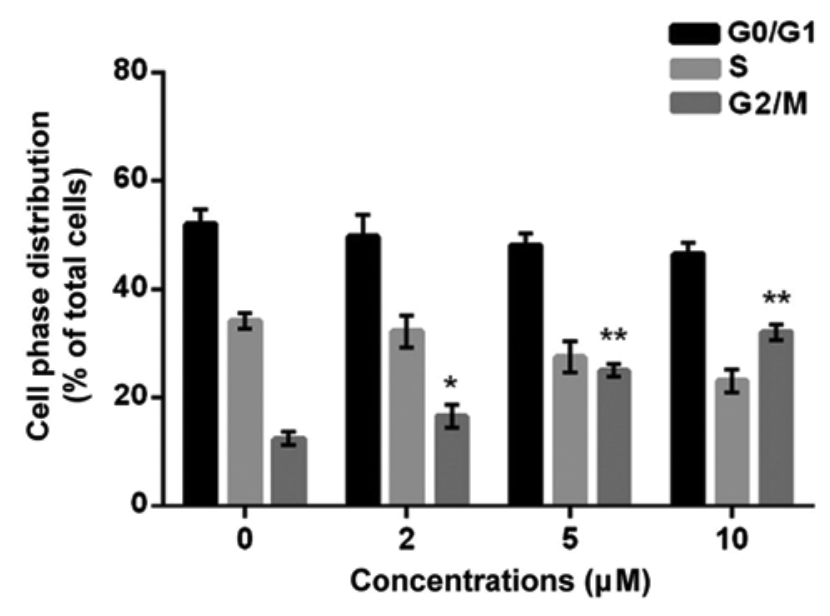

Figure 2. Effect of of corosolic acid (CA) on cell cycle distribution in human retinoblastoma Y-79 cells. Cells were treated with various concentrations of CA $(0,2,5$ and $10 \mu \mathrm{M})$ for $24 \mathrm{~h}$. (A) Cell cycle distribution was assessed by flow cytometric analysis. (B) The percentage of cells in each cell cycle phase following the various treatments. All data are expressed as means $\pm \mathrm{SD}$ of three experiments and each experiment included triplicate repeats. ${ }^{*} \mathrm{P}<0.05,{ }^{* *} \mathrm{P}<0.01$ vs. the control.
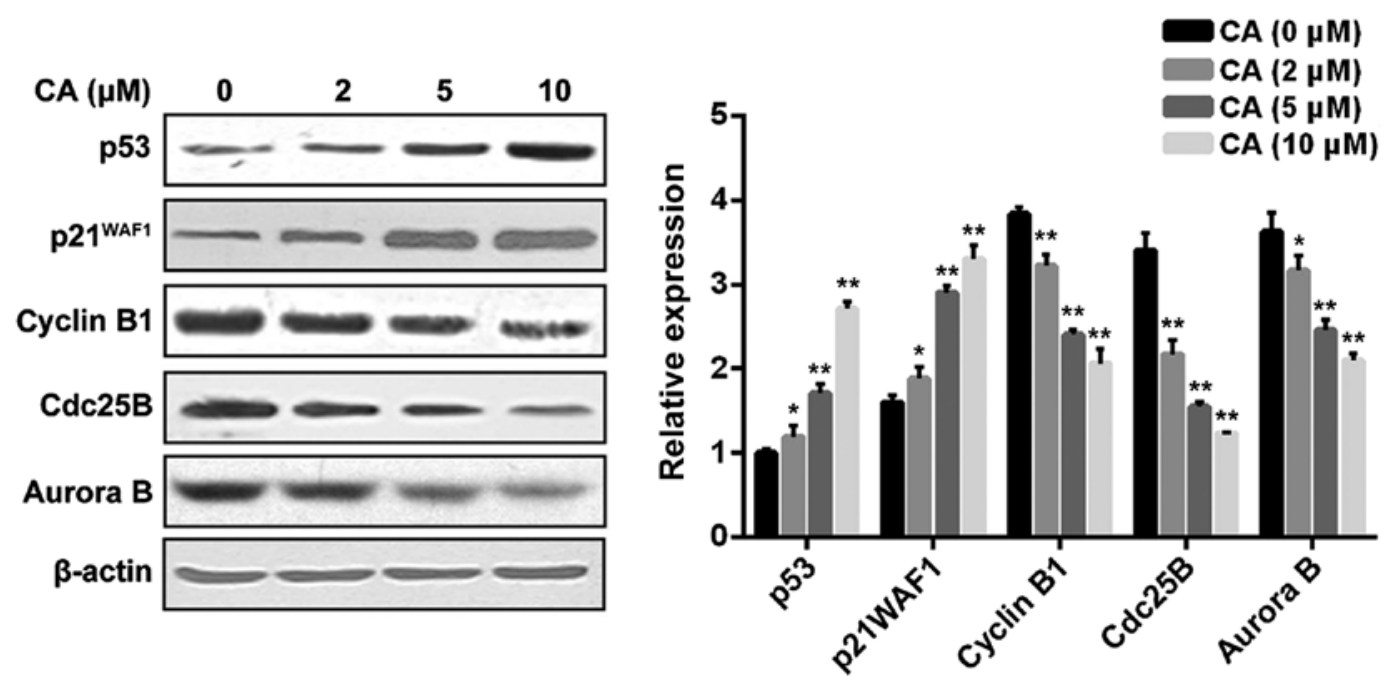

Figure 3. Regulatory effect of of corosolic acid (CA) on cell cycle regulators in human retinoblastoma Y-79 cells. Cells were treated with various concentrations of CA $(0,2,5$ and $10 \mu \mathrm{M})$ for $24 \mathrm{~h}$. The protein levels were assessed by western blot analysis and the relative quantification of the protein levels was determined. All data are expressed as means $\pm \mathrm{SD}$ of three experiments and each experiment included triplicate repeats. ${ }^{*} \mathrm{P}<0.05,{ }^{* *} \mathrm{P}<0.01$ vs. the control.

CA treatment dose-dependently affected the MAPK pathway via inducing upregulation of ASK1 and phosphorylation of JNK and p38, but not ERK (data not shown).

Inhibitory effect of CA on MELK-FoxM1 signaling in human retinoblastoma Y-79 cells. A previous study estimated that FoxM1 is the direct target of UA (22). First, we examined the inhibitory effect of CA on the expression profiles of MELK and FoxM1. The results revealed that CA treatment for $24 \mathrm{~h}$ significantly suppressed the expression levels of MELK and FoxM1 in a dose-dependent manner in Y-79 cells (Fig. 6A). In addition, MELK overexpression did not affect the inhibitory effect of CA on FoxM1 expression; likewise FoxM1 overexpression did not affect the inhibitory effect of CA on MELK expression (Fig. 6B). Then, we examined the inhibitory effect of CA on the transcriptional activity of FoxM1. As shown in Fig. 7, CA treatment for $24 \mathrm{~h}$ significantly suppressed the transcriptional activity of FoxM1 in cells transfected with FoxM1 + MELK (-) or FoxM1 in a dose-dependent manner, indicating that CA abrogated FoxM1 activity driven by FoxM1 itself or MELK, and such a compound abrogated MELK-dependent FoxM1 activity possibly by inhibiting MELK expression.

MELK-FoxM1 signaling is involved in the inductive effect of $C A$ on cell cycle arrest and cell apoptosis in human retinoblastoma Y-79 cells. Several lines of evidence have suggested that MELK-FoxM1 signaling plays a key role in the process of cell cycle and cell apoptosis (27-29). To examine whether CA induces cell cycle arrest and cell apoptosis via regulating 
A

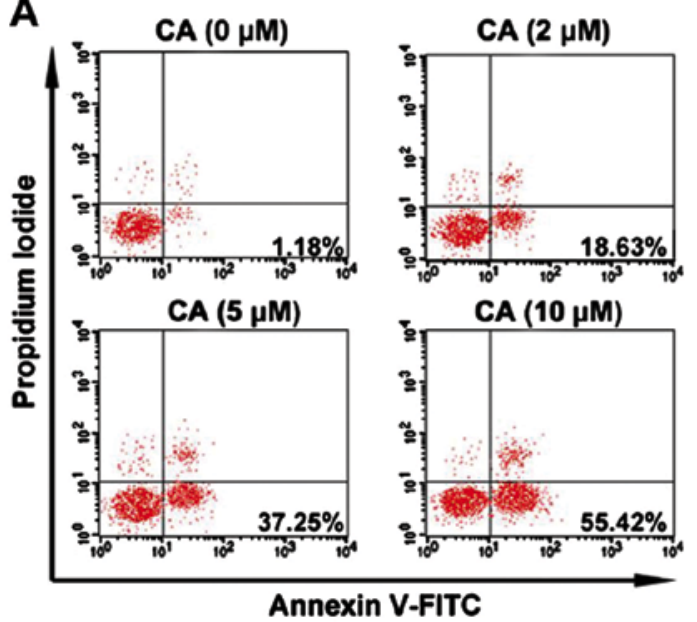

B

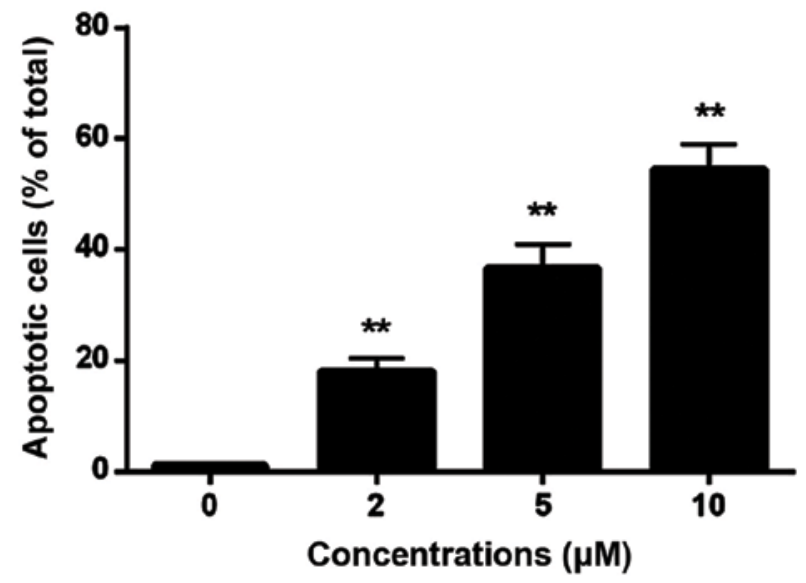

Figure 4. Effect of of corosolic acid (CA) on cell apoptosis in human retinoblastoma Y-79 cells. Cells were treated with various concentrations of CA ( $0,2,5$ and $10 \mu \mathrm{M}$ ) for $24 \mathrm{~h}$. (A) Cell apoptosis was assessed by flow cytometric analysis. (B) The percentage of apoptotic cells. All data are expressed as means \pm SD of three experiments and each experiment included triplicate repeats. ${ }^{* *} \mathrm{P}<0.01$ vs. the control.

A

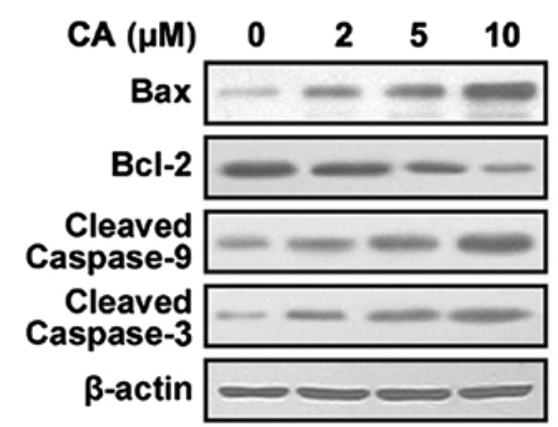

B

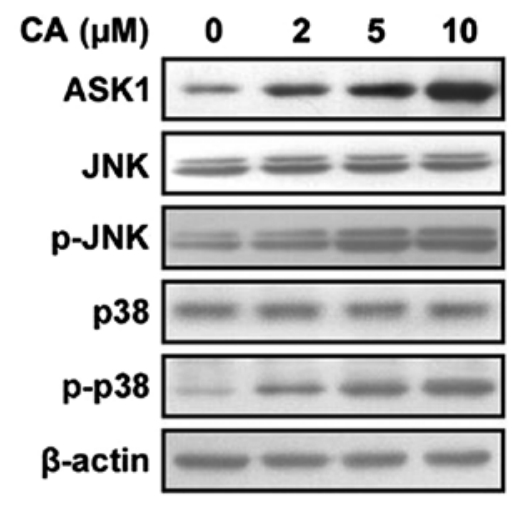

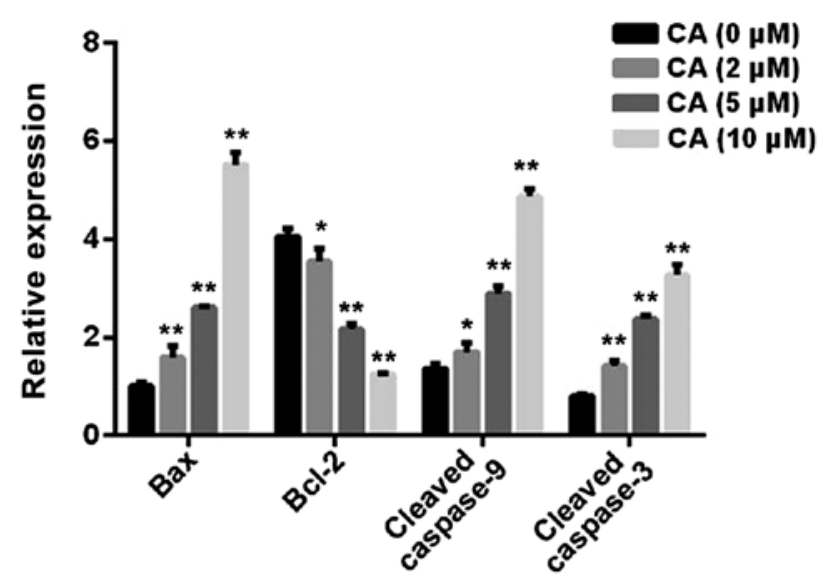

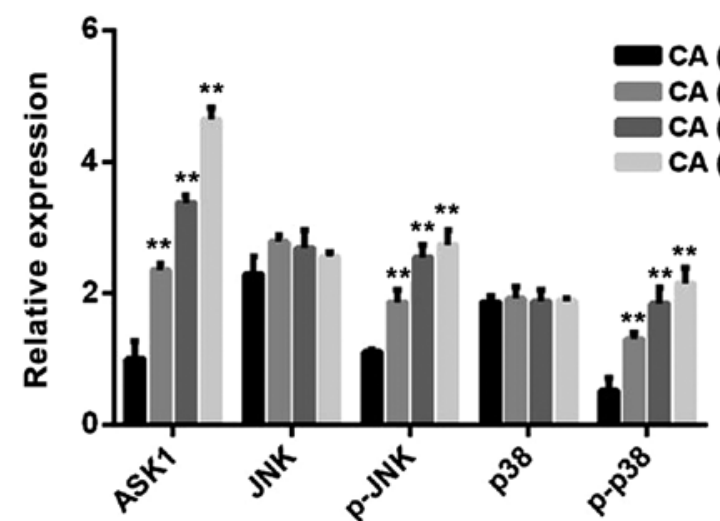

Figure 5. Regulatory effect of of corosolic acid (CA) on cell apoptosis regulators in human retinoblastoma Y-79 cells. Cells were treated with various concentrations of CA $(0,2,5$ and $10 \mu \mathrm{M})$ for $24 \mathrm{~h}$. The protein levels were assessed by western blot analysis and the relative quantification of the protein levels was determined. (A) The change in mitochondrial pathway mediators. (B) The change in MAPK pathway mediators. All data are expressed as means \pm SD of three experiments and each experiment included triplicate repeats. ${ }^{*} \mathrm{P}<0.05,{ }^{* *} \mathrm{P}<0.01$ vs. the control.

MELK-FoxM1 signaling, Y-79 cells were transfected with FoxM1 alone, MELK alone or MELK + FoxM1, and then treated with $\mathrm{CA}(10 \mu \mathrm{M})$ for $24 \mathrm{~h}$. The results indicated that overexpression of MELK + FoxM1, rather than FoxM1 alone, significantly reversed the inductive effect of CA on cell cycle arrest and cell apoptosis (Figs. 8A and 9A). However, overexpression of MELK alone slightly attenuated the inductive effect of CA compared to the other groups, indicating that MELK 

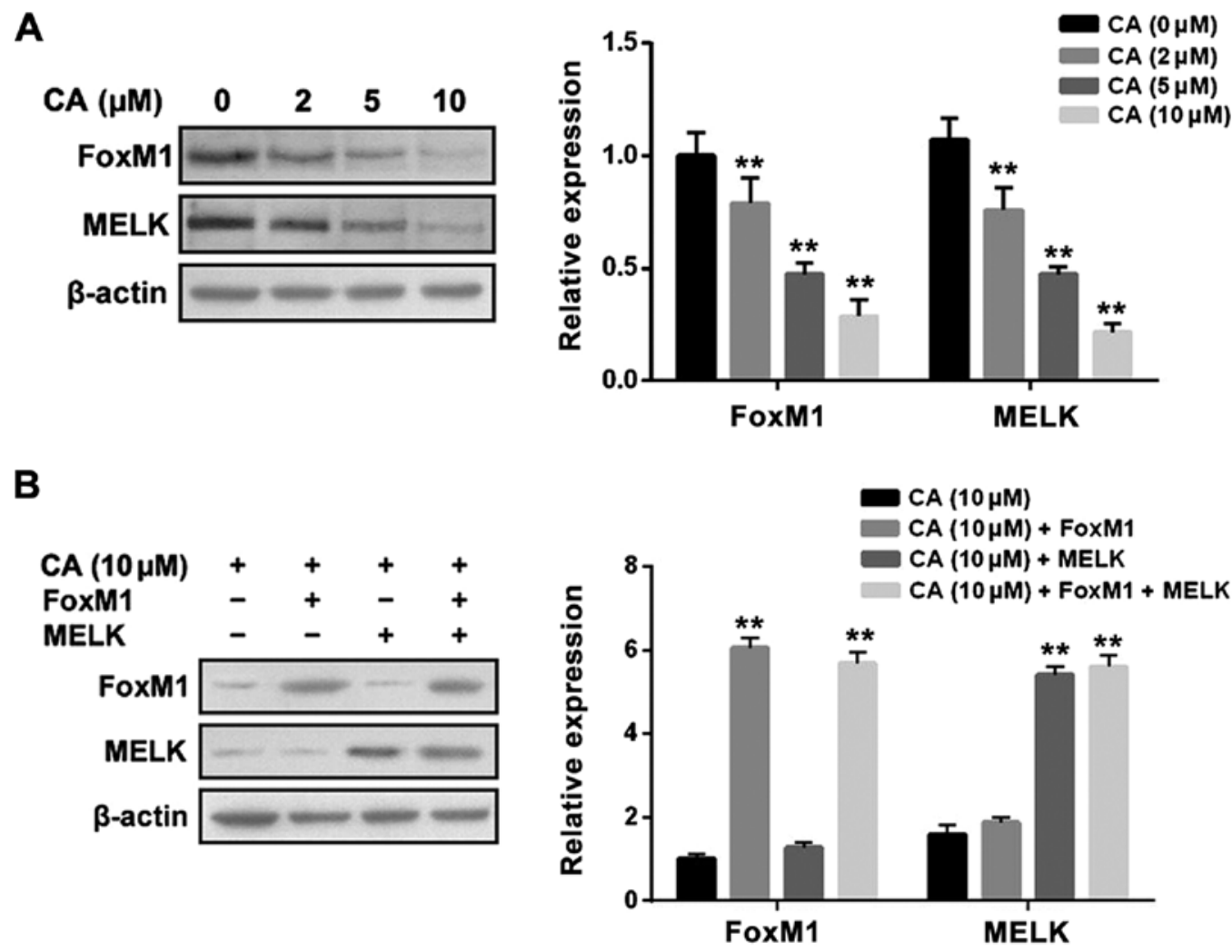

Figure 6. Effect of corosolic acid (CA) on the expression profiles of MELK and FoxM1 in human retinoblastoma Y-79 cells. (A) Cells were treated with various concentrations of CA $(0,2,5$ and $10 \mu \mathrm{M})$ for $24 \mathrm{~h}$. The expression levels of MELK and FoxM1 were assessed by western blot analysis and the relative quantification of the protein levels was determined. (B) Cells transfected with MELK alone, FoxM1 alone or MELK + FoxM1 were treated with $\mathrm{CA}(10 \mu \mathrm{M})$ for $24 \mathrm{~h}$. The expression levels of MELK and FoxM1 were assessed by western blot analysis and the relative quantification of the protein levels was determined. All data are expressed as means $\pm \mathrm{SD}$ of three experiments and each experiment included triplicate repeats. ${ }^{* *} \mathrm{P}<0.01$ vs. the control (A); ${ }^{* * *} \mathrm{P}<0.01$ vs. $\mathrm{CA}(10 \mu \mathrm{M})$ treatment (B).

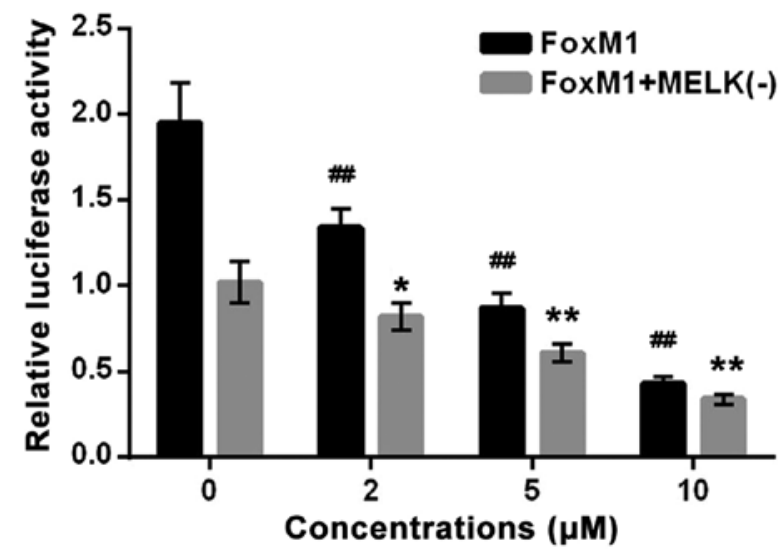

Figure 7. Effect of corosolic acid (CA) on the transcriptional activity of FoxM1 in retinoblastoma Y-79 cells. Cells were transfected with FoxM1-luc reporter vector as well as FoxM1 and MELK siRNA (FoxM1 + MELK(-) or FoxM1 alone and were then treated with CA $(0,2,5$ and $10 \mu \mathrm{M})$ for $24 \mathrm{~h}$, and the transcriptional activity of FoxM1 was assessed by luciferase assay. All data are expressed as means \pm SD of three experiments and each experiment included triplicate repeats. ${ }^{*} \mathrm{P}<0.05,{ }^{* * *} \mathrm{P}<0.01$ vs. the control, ${ }^{\# \#} \mathrm{P}<0.01$ vs. the control.

may exert its effect mainly through the FoxM1 pathway. In addition, the changes in related molecules were further investigated, and the results were consistent with the changes in cell cycle distribution and cell apoptosis (Figs. 8B and 9B and C).

\section{Discussion}

Corosolic acid (CA) has been assessed as a promising anticancer agent, and existing evidence has estimated that CA can affect a wide variety of human cancers, such as hepatocellular (30), colorectal (31) and gastric carcinoma (32). It has been reported that $\mathrm{CA}$ inhibits cell growth with lower $\mathrm{IC}_{50}$ values in some types of cancer cells when compared to these values for UA (17). To date, the effect of CA on human retinoblastoma cancer cells has never been explored. In the present study, we revealed that $\mathrm{CA}$ treatment significantly inhibited cell growth by inducing cell cycle arrest and cell apoptosis in Y-79 cells, an in vitro model of human retinoblastoma. As an analog of UA, CA markedly changed the expression profiles of FoxM1 and its downstream effectors, which include cell cycle regulators such as p53, p21, cyclin B1, Cdc25B and Aurora B as well as cell apoptosis regulators from the mitochondrial and MAPK pathways. However, the precise mechanism attributed to the cytotoxic effect of CA on Y-79 cells remained inconclusive.

FoxM1 plays a critical role in the regulation of various biological processes (33) In vitro, loss of FoxM1 results in cell cycle arrest and subsequent defective mitotic spindle integrity; in vivo, loss of FoxM1 leads toembryonic lethality due to a failure to enter mitosis (34). Existing evidence has shown that FoxM1 deregulation is associated with cancer progression and cancer drug resistance (35). Aytes et al (36) demonstrated the FoxM1 target gene CENPF can synergistically interact with FoxM1 to 

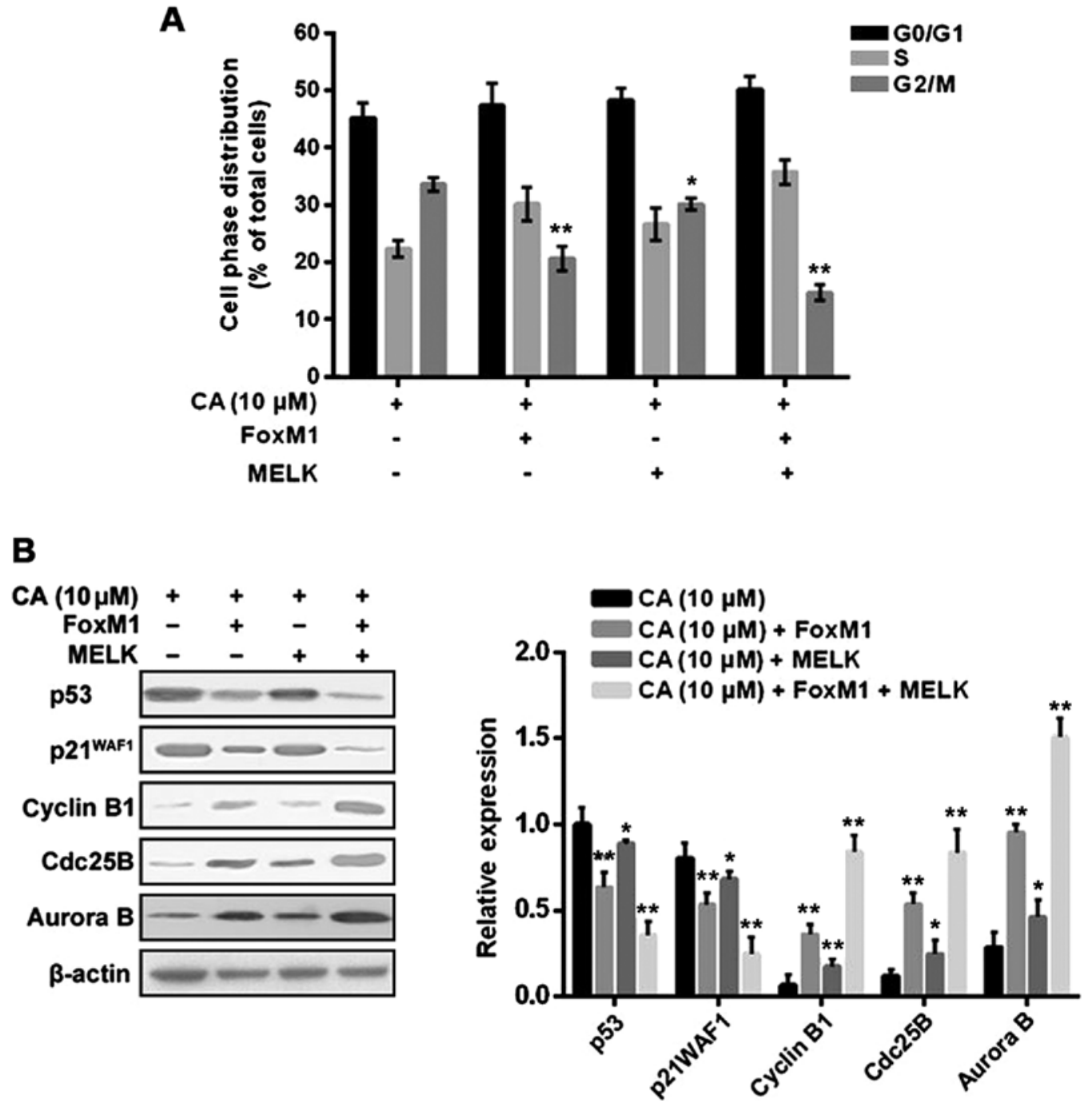

Figure 8. Involvement of MELK-FoxM1 signaling in the inductive effect of corosolic acid (CA) on cell cycle arrest in human retinoblastoma Y-79 cells. Cells transfected with FoxM1 alone, MELK alone and MELK+FoxM1 were treated with CA (10 $\mu \mathrm{M})$ for $24 \mathrm{~h}$. (A) Cell cycle distribution was assessed by flow cytometric analysis. (B) The expression levels of cell cycle regulators were assessed by western blot analysis and the relative quantification of the protein levels was determined. All data are expressed as means \pm SD of three experiments and each experiment included triplicate repeats. ${ }^{*} \mathrm{P}<0.05,{ }^{* * *} \mathrm{P}<0.01 \mathrm{vs}$. CA $(10 \mu \mathrm{M})$ treatment.

drive prostate cancer malignancy. Nestal de Moraes et al (37) showed that FoxM1 upregulates anti-apoptotic genes XIAP and survivin by interacting with their promoters, contributing to the chemoresistance of breast cancer. Therefore, FoxM1 has become an attractive therapeutic target in the fight against several lines of cancers. Existing evidence has confirmed that FoxM1 is a direct target of UA. In MCF-7 cancer cells, UA treatment inhibits the expression level of FoxM1, and FoxM1 inhibition by UA suppressed cell proliferation and induced cell cycle arrest (22). In the present study, treatment of CA, an analog of UA, significantly suppressed the expression level and the transcriptional activity of FoxM1; however, transfection of FoxM1 partially attenuated the cytotoxic effect of CA on Y-79 cells, indicating that FoxM1 was not the only target of this compound. MELK is a member of the AMPK/ Snf1 family, and elevated MELK expression is observed in various types of human cancer and is correlated with the poor prognosis of cancer patients (20,38). Wang et al (27) revealed that MELK is required for the transforming activity, survival and proliferation of basal-like breast cancer cells. Our results indicated that treatment of CA also significantly suppressed the expression level of MELK. However, transfection of MELK slightly attenuated the cytotoxic effect of CA on Y-79 cells, indicating that CA may exert its activity via inhibition of MELK combined with other related factors, rather than MELK alone. Joshi et al (21) reported that FoxM1 is a key substrate of MELK and MELK is essential for the phosphorylation and activation of FoxM1, which then results in a subsequent change in cell cycle and cell apoptosis regulatory genes. Xia et al (39) reported that MELK regulates cell cycle progression and mitosis-related genes mainly through activation of FoxM1. In the present study, we initially found that treatment of CA suppressed the expression levels of both MELK and FoxM1; however, there was no interaction between MELK expression and FoxM1 expression. We then found that treatment of CA suppressed the transcriptional activity of FoxM1 to the similar baseline level in cells transfected with FoxM1 + MELK(-) and in cells transfected with FoxM1 alone, which implied that 


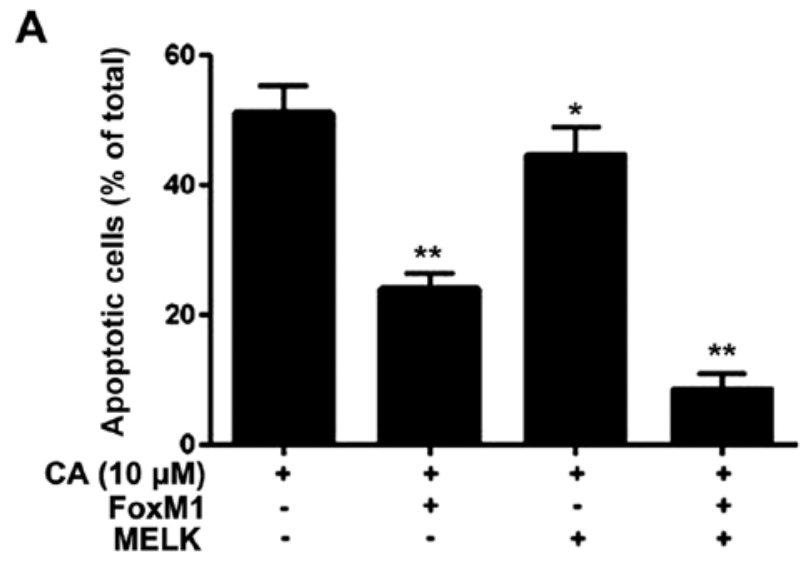

B
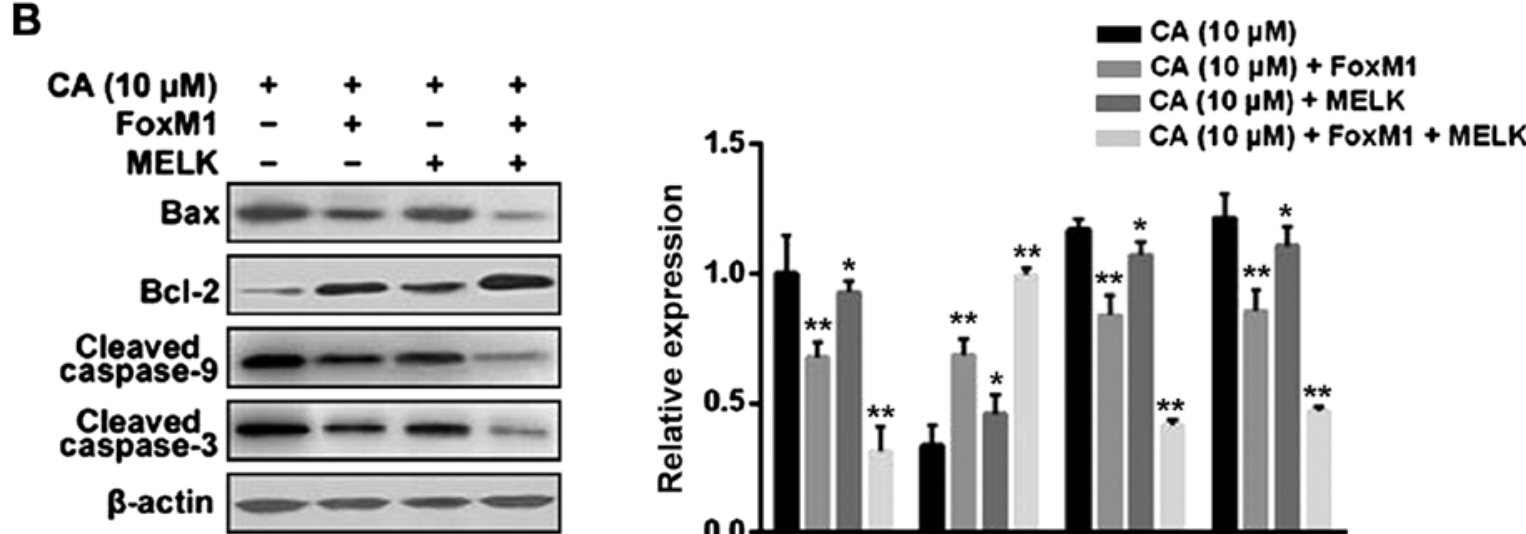

C
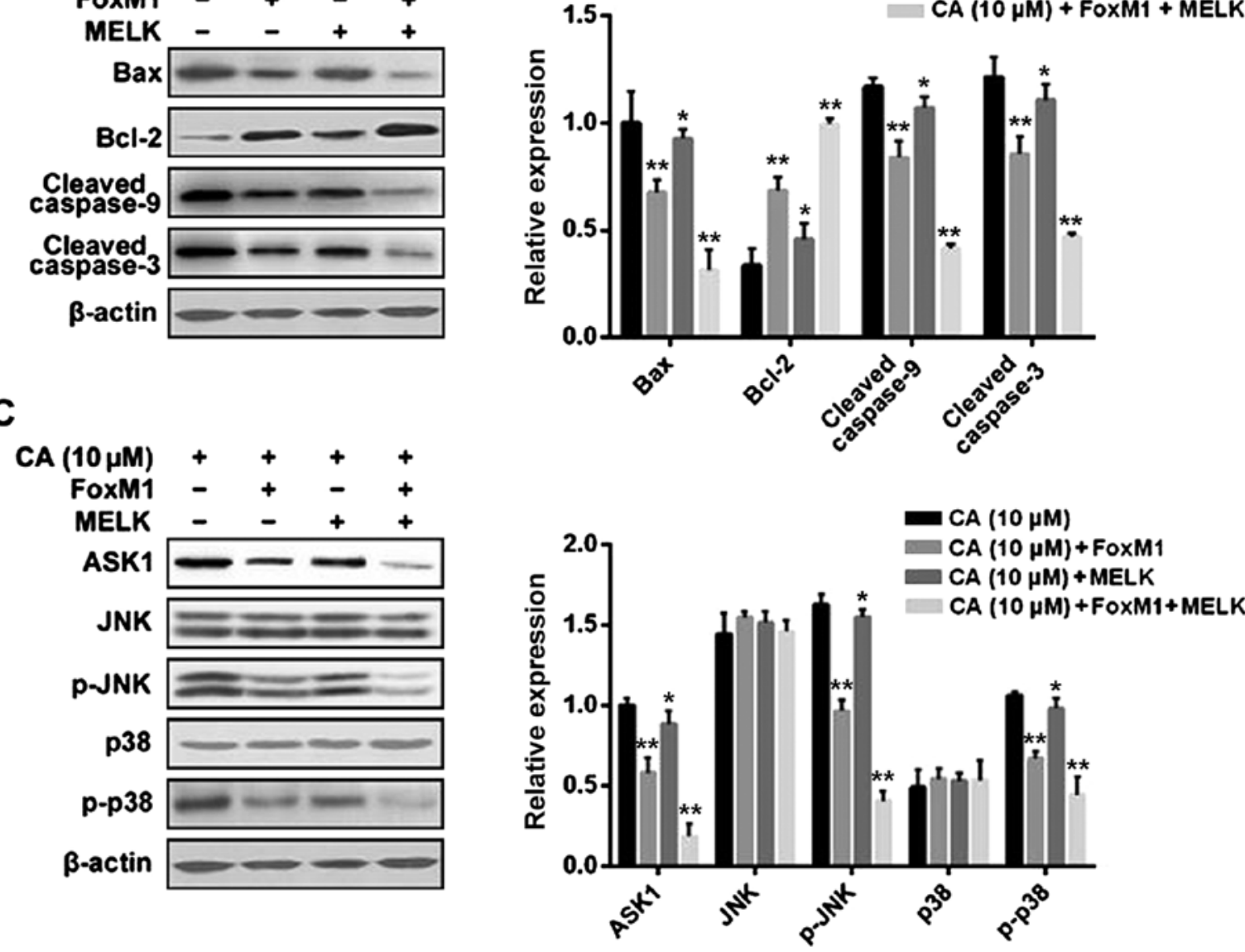

Figure 9. Involvement of MELK-FoxM1 signaling in the inductive effect of corosolic acid (CA) on cell apoptosis in human retinoblastoma Y-79 cells. Cells transfected with FoxM1 alone, MELK alone and MELK + FoxM1 were treated with CA (10 $\mu \mathrm{M})$ for $24 \mathrm{~h}$. (A) Cell apoptosis was assessed by flow cytometric analysis. (B) The expression levels of mitochondrial pathway mediators were assessed by western blot analysis and the relative quantification of the protein levels was determined. (C) The expression levels of MAPK pathway mediators were assessed by western blot analysis and the relative quantification of the protein levels was determined. All data are expressed as means $\pm \mathrm{SD}$ of three experiments and each experiment included triplicate repeats. ${ }^{*} \mathrm{P}<0.05$, ${ }^{* *} \mathrm{P}<0.01$ vs. CA $(10 \mu \mathrm{M})$ treatment.

CA abrogated FoxM1 activation driven by itself or MELK. Moreover, CA abrogated MELK-driven FoxM1 activity possibly by inhibiting MELK expression. Further study showed that transfection of both MELK and FoxM1, rather than FoxM1 alone, significantly attenuated the effect of CA. In addition, MELK transfection alone slightly attenuated the effect of CA on the cell cycle, cell apoptosis and the related mediators compared to FoxM1 transfection alone, indicating that MELK may exert its effect mainly via activating FoxM1. Collectively, we propose that CA exhibits cytotoxic effects on cell proliferation and a promotive effect on cell cycle arrest and cell apoptosis by inhibiting the expression levels of MELK and FoxM1 as well as suppressing the transcriptional activity of FoxM1 driven by itself or MELK. 
In summary, the present study revealed that MELK-FoxM1 signaling is a potential therapeutic target for human retinoblastoma, and provides novel insight into the potential application of corosolic acid and its derivatives in the treatment of this disease.

\section{Acknowledgements}

The authors thank Dr Fanfan Zhou for her technical support.

\section{Funding}

The present study was supported by grants from the National Significant New Drugs Creation Program (no. 2017ZX09304021), the Jiangsu Provincial Medical Innovation Team (no. CXTDA2017024), the Major Project of Wuxi Municipal Health Bureau (nos. ZS201401 and Z201508) and the Project of Wuxi Municipal Science and Technology Bureau (nos. CSE31N1520 and CSE31N1621).

\section{Availability of data and materials}

The datasets used during the present study are available from the corresponding author upon reasonable request.

\section{Authors' contributions}

KW, YY and MY contributed to the design of the study and wrote the manuscript. $\mathrm{KW}$ and $\mathrm{XZ}$ performed the experiments. FFZ analyzed the data. LZ performed the analysis with constructive discussions. All authors read and approved the manuscript and agree to be accountable for all aspects of the research in ensuring that the accuracy or integrity of any part of the work are appropriately investigated and resolved.

\section{Ethics approval and consent to participate}

Not applicable.

\section{Consent for publication}

Not applicable.

\section{Competing interests}

The authors declare that they have no competing interests.

\section{References}

1. Kivelä T: The epidemiological challenge of the most frequent eye cancer: Retinoblastoma, an issue of birth and death. Br J Ophthalmol 93: 1129-1131, 2009.

2. Park SJ, Woo SJ and Park KH: Incidence of retinoblastoma and survival rate of retinoblastoma patients in Korea using the Korean National Cancer Registry database (1993-2010). Invest Ophthalmol Vis Sci 55: 2816-2821, 2014.

3. Waddell KM, Kagame K, Ndamira A, Twinamasiko A, Picton SV, Simmons IG, Johnston WT and Newton R: Clinical features and survival among children with retinoblastoma in Uganda. Br J Ophthalmol 99: 387-390, 2015

4. McEvoy JD and Dyer MA: Genetic and epigenetic discoveries in human retinoblastoma. Crit Rev Oncog 20: 217-225, 2015.
5. DiCiommo D, Gallie BL and Bremner R: Retinoblastoma: The disease, gene and protein provide critical leads to understand cancer. Semin Cancer Biol 10: 255-269, 2000.

6. Meel R, Radhakrishnan V and Bakhshi S: Current therapy and recent advances in the management of retinoblastoma. Indian $\mathbf{J}$ Med Paediatr Oncol 33: 80-88, 2012.

7. Kim JY and Park Y: Treatment of Retinoblastoma: The role of external beam radiotherapy. Yonsei Med J 56: 1478-1491, 2015.

8. Ye J, Lou L, Jin K, Xu Y, Ye X, Moss T and McBain H: Vision-related quality of life and appearance concerns are associated with anxiety and depression after eye enucleation: A cross-sectional study. PLoS One 10: e0136460, 2015.

9. Marees T, Moll AC, Imhof SM, de Boer MR, Ringens PJ and van Leeuwen FE: Risk of second malignancies in survivors of retinoblastoma: More than 40 years of follow-up. J Natl Cancer Inst 100: 1771-1779, 2008.

10. Temming P, Arendt M, Viehmann A, Eisele L, Le Guin CH, Schündeln MM, Biewald E, Astrahantseff K, Wieland R, Bornfeld $\mathrm{N}$, et al: Incidence of second cancers after radiotherapy and systemic chemotherapy in heritable retinoblastoma survivors: A report from the German reference center. Pediatr Blood Cancer 64: 71-80, 2017.

11. Mazumder K, Tanaka K and Fukase K: Cytotoxic activity of ursolic acid derivatives obtained by isolation and oxidative derivatization. Molecules 18: 8929-8944, 2013.

12. Shan JZ, Xuan YY, Zheng S, Dong Q and Zhang SZ: Ursolic acid inhibits proliferation and induces apoptosis of HT-29 colon cancer cells by inhibiting the EGFR/MAPK pathway. J Zhejiang Univ Sci B 10: 668-674, 2009.

13. Leng S, Hao Y, Du D, Xie S, Hong L, Gu H, Zhu X, Zhang J, Fan D and Kung HF: Ursolic acid promotes cancer cell death by inducing Atg5-dependent autophagy. Int J Cancer 133: 2781-2790, 2013.

14. Kim SH, Ryu HG, Lee J, Shin J, Harikishore A, Jung HY, Kim YS, Lyu HN, Oh E, Baek NI, et al: Ursolic acid exerts anti-cancer activity by suppressing vaccinia-related kinase 1-mediated damage repair in lung cancer cells. Sci Rep 5: 14570, 2015.

15. Weng H, Tan ZJ, Hu YP, Shu YJ, Bao RF, Jiang L, Wu XS, Li ML, Ding Q, Wang XA, et al: Ursolic acid induces cell cycle arrest and apoptosis of gallbladder carcinoma cells. Cancer Cell Int 14: 96, 2014.

16. Huang CY, Lin CY, Tsai CW and Yin MC: Inhibition of cell proliferation, invasion and migration by ursolic acid in human lung cancer cell lines. Toxicol In Vitro 25: 1274-1280, 2011.

17. Sung B, Kang YJ, Kim DH, Hwang SY, Lee Y, Kim M, Yoon JH, Kim CM, Chung HY and Kim ND: Corosolic acid induces apoptotic cell death in HCT116 human colon cancer cells through a caspase-dependent pathway. Int J Mol Med 33: 943-949, 2014.

18. Zona S, Bella L, Burton MJ, Nestal de Moraes G and Lam EW: FOXM1: An emerging master regulator of DNA damage response and genotoxic agent resistance. Biochim Biophys Acta 1839: 1316-1322, 2014

19. Koo CY, Muir KW and Lam EW: FOXM1: From cancer initiation to progression and treatment. Biochim Biophys Acta 1819: 28-37, 2012.

20. Ganguly R, Mohyeldin A, Thiel J, Kornblum HI, Beullens M and Nakano I: MELK - a conserved kinase: Functions, signaling, cancer, and controversy. Clin Transl Med 4: 11, 2015.

21. Joshi K, Banasavadi-Siddegowda Y, Mo X, Kim SH, Mao P, Kig C, Nardini D, Sobol RW, Chow LM, Kornblum HI, et al: MELK-dependent FOXM1 phosphorylation is essential for proliferation of glioma stem cells. Stem Cells 31: 1051-1063, 2013.

22. Wang JS, Ren TN and Xi T: Ursolic acid induces apoptosis by suppressing the expression of FoxM1 in MCF-7 human breast cancer cells. Med Oncol 29: 10-15, 2012.

23. van Meerloo J, Kaspers GJ and Cloos J: Cell sensitivity assays: The MTT assay. Methods Mol Biol 731: 237-245, 2011.

24. Zhu X, Wang K, Zhang K, Zhang T, Yin Y and Xu F: Ziyuglycoside I inhibits the proliferation of MDA-MB-231 breast carcinoma cells through Inducing p53-mediated G2/M cell cycle arrest and intrinsic/extrinsic apoptosis. Int J Mol Sci 17: 1903, 2016.

25. Wang K, Zhu X, Zhang K, Wu Z, Sun S, Zhou F and Zhu L: Neuroprotective effect of puerarin on glutamate-induced cytotoxicity in differentiated Y-79 cells via inhibition of ROS generation and $\mathrm{Ca}^{2+}$ influx. Int J Mol Sci 17: E1109, 2016.

26. Smale ST: Luciferase assay. Cold Spring Harb Protoc 2010: pdb prot5421. doi: 10.1101/pdb.prot5421. 
27. Wang Y, Lee YM, Baitsch L, Huang A, Xiang Y, Tong H, Lako A Von T, Choi C, Lim E, et al: MELK is an oncogenic kinase essential for mitotic progression in basal-like breast cancer cells. eLife 3: e01763, 2014

28. Lin ML, Park JH, Nishidate T, Nakamura Y and Katagiri T: Involvement of maternal embryonic leucine zipper kinase (MELK) in mammary carcinogenesis through interaction with Bcl-G, a pro-apoptotic member of the Bcl-2 family. Breast Cancer Res 9: R17,2007.

29. Jiang L, Wang P, Chen L and Chen H: Down-regulation of FoxM1 by thiostrepton or small interfering RNA inhibits proliferation, transformation ability and angiogenesis, and induces apoptosis of nasopharyngeal carcinoma cells. Int J Clin Exp Pathol 7: $5450-5460,2014$.

30. Ku CY, Wang YR, Lin HY, Lu SC and Lin JY: Corosolic acid inhibits hepatocellular carcinoma cell migration by targeting the VEGFR2/Src/FAK pathway. PLoS One 10: e0126725, 2015.

31. Yoo KH, Park JH, Lee DY, Hwang-Bo J, Baek NI and Chung IS Corosolic acid exhibits anti-angiogenic and anti-lymphangiogenic effects on in vitro endothelial cells and on an in vivo CT-26 colon carcinoma animal model. Phytother Res 29: 714-723, 2015.

32. Lee HS, Park JB, Lee MS, Cha EY, Kim JY and Sul JY: Corosolic acid enhances 5-fluorouracil-induced apoptosis against SNU-620 human gastric carcinoma cells by inhibition of mammalian target of rapamycin. Mol Med Rep 12: 4782-4788, 2015.

33. Wierstra I: The transcription factor FOXM1 (Forkhead box M1) Proliferation-specific expression, transcription factor function, target genes, mouse models, and normal biological roles. Adv Cancer Res 118: 97-398, 2013
34. Laoukili J, Kooistra MR, Brás A, Kauw J, Kerkhoven RM, Morrison A, Clevers H and Medema RH: FoxM1 is required for execution of the mitotic programme and chromosome stability. Nat Cell Biol 7: 126-136, 2005.

35. Wierstra I: FOXM1 (Forkhead box M1) in tumorigenesis: Overexpression in human cancer, implication in tumorigenesis, oncogenic functions, tumor-suppressive properties, and target of anticancer therapy. Adv Cancer Res 119: 191-419, 2013.

36. Aytes A, Mitrofanova A, Lefebvre C, Alvarez MJ, Castillo-Martin M, Zheng T, Eastham JA, Gopalan A, Pienta KJ, Shen MM, et al: Cross-species regulatory network analysis identifies a synergistic interaction between FOXM1 and $C E N P F$ that drives prostate cancer malignancy. Cancer Cell 25: 638-651, 2014.

37. Nestal de Moraes G, Delbue D, Silva KL, Robaina MC, Khongkow P, Gomes AR, Zona S, Crocamo S, Mencalha AL, Magalhães LM, et al: FOXM1 targets XIAP and Survivin to modulate breast cancer survival and chemoresistance. Cell Signal 27: 2496-2505, 2015.

38. Ganguly R, Hong CS, Smith LG, Kornblum HI and Nakano I: Maternal embryonic leucine zipper kinase: Key kinase for stem cell phenotype in glioma and other cancers. Mol Cancer Ther 13: 1393-1398, 2014

39. Xia H, Kong SN, Chen J, Shi M, Sekar K, Seshachalam VP, Rajasekaran M, Goh BKP, Ooi LL and Hui KM: MELK is an oncogenic kinase essential for early hepatocellular carcinoma recurrence. Cancer Lett 383: 85-93, 2016. 